\title{
Consequences of coronavirus disease 2019 on international medical graduates and students applying to residencies in the United States
}

\author{
Jewel Park ${ }^{1}$ and Hye Chang Rhim ${ }^{2}$ \\ ${ }^{1}$ Korea University College of Medicine and ${ }^{2}$ Department of Orthopedic Surgery, Korea University Anam Hospital, \\ Seoul, Korea
}

\section{Introduction}

The coronavirus disease 2019 (COVID-19) pandemic has necessitated unprecedented measures to contain the virus, including restricting foreigners from entering the United States. Since January 31, 2020, several presidential proclamations have sequentially restricted the entry of foreign nationals from China, Iran, and much of Europe; and as of March 20, the Department of State has temporarily suspended routine visa services at all US Embassies and Consulates [1]. Previous immigration restrictions, such as Presidential Proclamation 9645 in 2018, had already raised concerns about hindering the entrance of international medical graduates (IMGs), who constitute $25 \%$ of the physician workforce in the United States [2].

According to the National Resident Matching Program (NRMP), also known as the Match, approximately 7,000
non-US IMGs, in addition to 5,000 US IMGs, apply for residencies in the United States every year, citing various reasons such as greater professional opportunities, a better training environment, or political stability [3]. The application process for IMGs is complex and rigorous, often requiring several years after graduation from medical school, and it is inherently unpredictable, with only $60 \%$ of applicants matched successfully [4]. Thus, the process is especially vulnerable to perturbations such as the current pandemic, and the consequences will negatively affect not only the flow of the physician workforce into the United States, but also the career fulfillment of IMGs and bilateral exchange of knowledge between the United States and other countries [5].

While the negative impacts of the pandemic on the residency application process may be minimal if the pandemic is controlled in the near future, estimates suggest the spread of COVID-19 in the United States will
Received: March 30, 2020 • Revised: April 8, 2020 • Accepted: April 13, 2020 Corresponding Author: Jewel Park (https://orcid.org/0000-0003-1375-3565) Korea University College of Medicine, 73 Goryeodae-ro, Seongbuk-gu, Seoul 02841, Korea Tel: +82.2.2286.1101 Fax: +82.2.2286.1104 email: bakjewel@korea.ac.kr
Korean J Med Educ 2020 Mar; 32(2): 91-95.

https://doi.org/10.3946/kjme.2020.156

eISSN: 2005-7288

(C) The Korean Society of Medical Education. All rights reserved. This is an open-access article distributed under the terms of the Creative Commons Attribution Non-Commercial License (http:// creativecommons.org/licenses/by-nc/3.0/), which permits unrestricted non-commercial use, distribution, and reproduction in any medium, provided the original work is properly cited. 
peak in June 2020, and due to the risk of rebound transmission, widespread social distancing will need to be maintained for at least 18 months, until vaccines are available to immunize the population [6]. Here, we summarize the potential consequences of the COVID-19 pandemic on the process of medical residency applications for current IMGs and international medical students (IMSs) and recommend measures that can be taken to minimize the disruption to their participation in US healthcare.

\section{International medical graduates plann- ing to apply for the 2021 Match}

Many steps in the process of residency application for IMGs require that applicants be physically present in the United States, such as the Step 2 clinical skills (CS) and Step 3 exam, and complete residency interviews. Also, although it is not compulsory, many IMGs participate in observerships/externships or research in the United States to increase their competitiveness. All these activities can be severely affected by the current travel restrictions.

The Step 2 CS exam is particularly important. Given the unavoidable human-to-human contact that takes place during the exam, the United States Medical Licensing Examination (USMLE) program has closed all of its five test centers as of March 16, 2020, and plans to reopen them on June 1 at the earliest [7]. While the USMLE program, after reopening, "will open additional testing appointments to help meet increased, timesensitive testing demands," not only is there a possibility that the reopening will be significantly delayed given the uncertain trajectory of the current pandemic, but a great practical difficulty is likely to arise in the plan to offer additional appointments, as the number of trained standardized patients (SPs) is limited and may even decrease if SPs decline to participate due to health concerns.

This problem is especially significant because Step 2 CS testing appointments are already notorious for being extremely limited and completely fill up at least 3 to 4 months in advance. Moreover, score reporting can take up to 3 months, which means that test appointments have to be scheduled very early on to meet the deadlines set by residency programs. The process is even more complicated for non-US IMGs, who have to apply for a visa just to take the exam. With the current suspension of visa services, many IMGs will find it difficult to secure a date that will enable them to meet the deadlines, and consequently, they may have to forego applying for the 2021 Match.

Since the trajectory of the current pandemic is unpredictable, a delay in reopening the USMLE test centers seems inevitable. Therefore, plans for reopening should be prepared and announced in a timely manner to avoid critical disruptions to the application process. Recently, objective structured clinical examinations were successfully carried out in Singapore during the COVID-19 pandemic whilst ensuring the safety of the participants [8]. Since the scale of the outbreak and the examination system is much larger in the United States, the experience in Singapore may not be applicable to the United States at present, but it at least suggests that with adequate preparation and coordination, restarting Step 2 CS examinations may be viable as the outbreak in the United States becomes more controlled.

We offer some suggestions to help minimize the disruption of IMG participation in the 2021 Match and address the grim situation in the United States, which, as of April 9, 2020, has the highest number of confirmed COVID-19 cases in the world. The State of New Jersey, which currently has the second highest number of cases 
in the United States, has granted temporary medical licenses to doctors who are licensed and in good standing in foreign countries [9]. If such measures are extended to other states that are severely affected by COVID-19, it will help to mitigate the acute physician shortages in these states, while allowing IMGs to enter the United States and take the Step 2 CS exam when the USMLE test centers reopen. Immigration policies would have to be temporarily modified to allow IMGs into the United States, and the offer could be limited to IMGs who have already completed USMLE Steps 1 and 2 clinical knowledge, to prevent the excessive entry of doctors with inadequate accreditation.

The residency application timeline for medical school students in the United States has also been severely affected by the cancellations of exams and clinical rotations due to COVID-19. Accordingly, questions have been raised as to whether the timeline of the 2021 Match could be delayed [10]. While implementing a delay would be complex and would require coordination among residency programs, the NRMP, and immigration services, it would also allow time for many applicants to receive their Step 2 CS results before applying to residency programs, many of which require the scores at the time of application between September and November. At the very least, these residency programs should consider extending the deadline for Step 2 CS scores to a more feasible date, such as the rank order list deadline, which is usually around the end of February. Alternatively, authorities may consider granting a temporary waiver in the 2021 Match for Step 2 CS qualification to allopathic US medical students, for whom the need for the accreditation has comparatively less utility given the first-time pass rate of 98\% [11]; this will solve the issue of the limited availability of Step 2 CS test appointments, which is currently putting US and international applicants alike at risk of not meeting the application deadline.

\section{Current international medical students}

For IMSs who have yet to graduate, the cancellation of visiting electives in the United States is the gravest concern. Due to safety concerns arising from the COVID-19 pandemic, many medical schools in the United States have cancelled clinical rotations and stopped receiving visiting students. As of April 7, 2020, out of the 41 schools that reported their policies on visiting students to the Association of American Medical Colleges, 28 schools are not receiving visiting students [12]. It is uncertain when these medical schools will start receiving visiting medical students again.

In addition to the well-recognized advantage of participating in visiting electives for successful candidacy in the Match [13], visiting electives benefit IMSs as the only way to gain hands-on clinical experience in the United States and receive letters of recommendation for their performance. Many programs specify that IMGs must have a minimum length of clinical experience and letters of recommendation from US physicians. IMGs are allowed to participate in visiting electives only in their final year of medical school, and while they can participate in observerships or externships after graduation, these are frequently not recognized as US clinical experiences by residency programs. Furthermore, the recent change in USMLE Step 1 reporting from three-digit scores to a pass/fail grade is expected to increase the importance of visiting electives and letters of recommendation for IMSs, since they now have lost one important objective measure attesting to their clinical competency [14].

Applying to a visiting elective in the United States is already a difficult and stressful process for IMSs, due to 
visa issues, financial burdens, incompatibility with the home institution's curriculum, and the extremely limited number of schools that offer visiting electives to international students (just before the pandemic, only 21 medical schools offered spots for IMSs from institutions without affiliation agreements). Since many IMSs solidify their intent to practice medicine in the United States after completing a visiting elective, medical schools and associated governing bodies in the United States should consider accommodating these students as much as possible. Rather than altogether cancelling the electives in the next few weeks, programs can reschedule the electives to a later date. Further, instead of stopping the receipt of new applications indefinitely, programs can continue to receive them and grant acceptance when the virus becomes sufficiently contained.

\section{Conclusion}

Every year, a large number of highly motivated IMGs seek training in the United States, and they play an important role in US health care. Their road to residency is lengthy and complex, and the travel restrictions and cessation of visiting programs in response to the COVID-19 pandemic are likely to severely disrupt the process. The unprecedented magnitude of the pandemic calls for corresponding modifications in the US medical system to accommodate for its ramifications. Timely execution of the abovementioned suggestions may hopefully minimize any disruptions to the IMG residency application process and to US healthcare.

\section{ORCID:}

Jewel Park: https://orcid.org/0000-0003-1375-3565;

Hye Chang Rhim: https://orcid.org/0000-0002-7986-6493
Acknowledgements: None.

Funding: No funding was obtained for this study.

Conflicts of interest: No potential conflict of interest relevant to this article was reported.

Author contributions: Conception or design of the work: JP; data analysis and interpretation: JP; drafting the article: JP; critical revision of the article: HCR; completion of the article: JP; and final approval of the version to be published: all authors.

\section{References}

1. U.S. Department of State. Current outbreak of coronavirus disease 2019. https://travel.state.gov/content/ travel/en/traveladvisories/ea/covid-19-information.html. Accessed March 23, 2020.

2. Radabaugh CL, Welcher CM, Skochelak SE. Long-term potential implications of immigration barriers for medical education. JAMA. 2019;321(8):741-742.

3. Chen PG, Nunez-Smith M, Berg D, Gozu A, Rulisa S, Curry LA. International medical graduates in the USA: a qualitative study on perceptions of physician migration. BMJ Open. 2011;1(2):e000138.

4. Saeed F, Majeed MH, Kousar N. Easing international medical graduates' entry into US training. J Grad Med Educ. $2011 ; 3(2): 269$.

5. Pinsky WW. The importance of international medical graduates in the United States. Ann Intern Med. 2017;166(11):840-841.

6. COVID-19 Response Team, Imperial College London. Impact of non-pharmaceutical interventions (NPIs) to reduce COVID-19 mortality and healthcare demand. https://www.imperial.ac.uk/media/imperial-college/medici ne/sph/ide/gida-fellowships/Imperial-College-COVID19-N PI-modelling-16-03-2020.pdf. Published March 2020. Accessed March 16, 2020. 
7. United States Medical Licensing Examination. COVID19 updates and resources. https://www.usmle.org/ frequently-asked-questions/\#covid19. Published April 2020. Accessed April 7, 2020.

8. Boursicot K, Kemp S, Ong $\mathrm{TH}$, et al. Conducting a high-stakes OSCE in a COVID-19 environment. MedEdPublish. 2020;9(1):54.

9. State of New Jersey. Governor Murphy signs executive order to remove barriers to health care professionals joining New Jersey's COVID-19 response and provide protections for Front Line health care responders. https://www.nj.gov/governor/news/news/562020/2020040 Ib.shtml. Published April 2020. Accessed April 9, 2020.

10. National Resident Matching Program. NRMP FAQs during COVID-19 pandemic. http:/www.nrmp.org/ covid-faqs/. Published April 2020. Accessed April 7, 2020.

11. Alvin MD. The USMLE Step 2 CS: time for a change. Med Teach. 2016;38(8):854-856.

12. Association of American Medical Colleges. VSLO Program updates. https://students-residents.aamc.org/ attending-medical-school/article/vslo-program-updates/. Accessed April 7, 2020.

13. Jacobson RA, Daly SC, Schmidt JL, et al. The impact of visiting student electives on surgical match outcomes. J Surg Res. 2015;196(2):209-215.

14. Desai A, Hegde A, Das D. Change in reporting of USMLE Step 1 scores and potential implications for international medical graduates. JAMA. 2020 Mar 6 [Epub]. https://doi.org/10.1001/jama.2020.2956. 